\title{
Conformance Control in Oil Reservoirs by Citric Acid-Coated Magnetite Nanoparticles
}

Hassan Divandari a, Abdolhossein Hemmati-Sarapardeh a, b, ${ }^{\text {, }}$, Mahin Schaffie a, Maen M. Husein c," , Mohammad Ranjbar ${ }^{\mathrm{a}}$

${ }^{a}$ Department of Petroleum Engineering, Shahid Bahonar University of Kerman, Kerman, Iran

${ }^{b}$ College of Construction Engineering, Jilin University, Changchun, China

${ }^{c}$ Department of Chemical \& Petroleum Engineering, University of Calgary, Calgary, AB T2N 1N4, Canada 


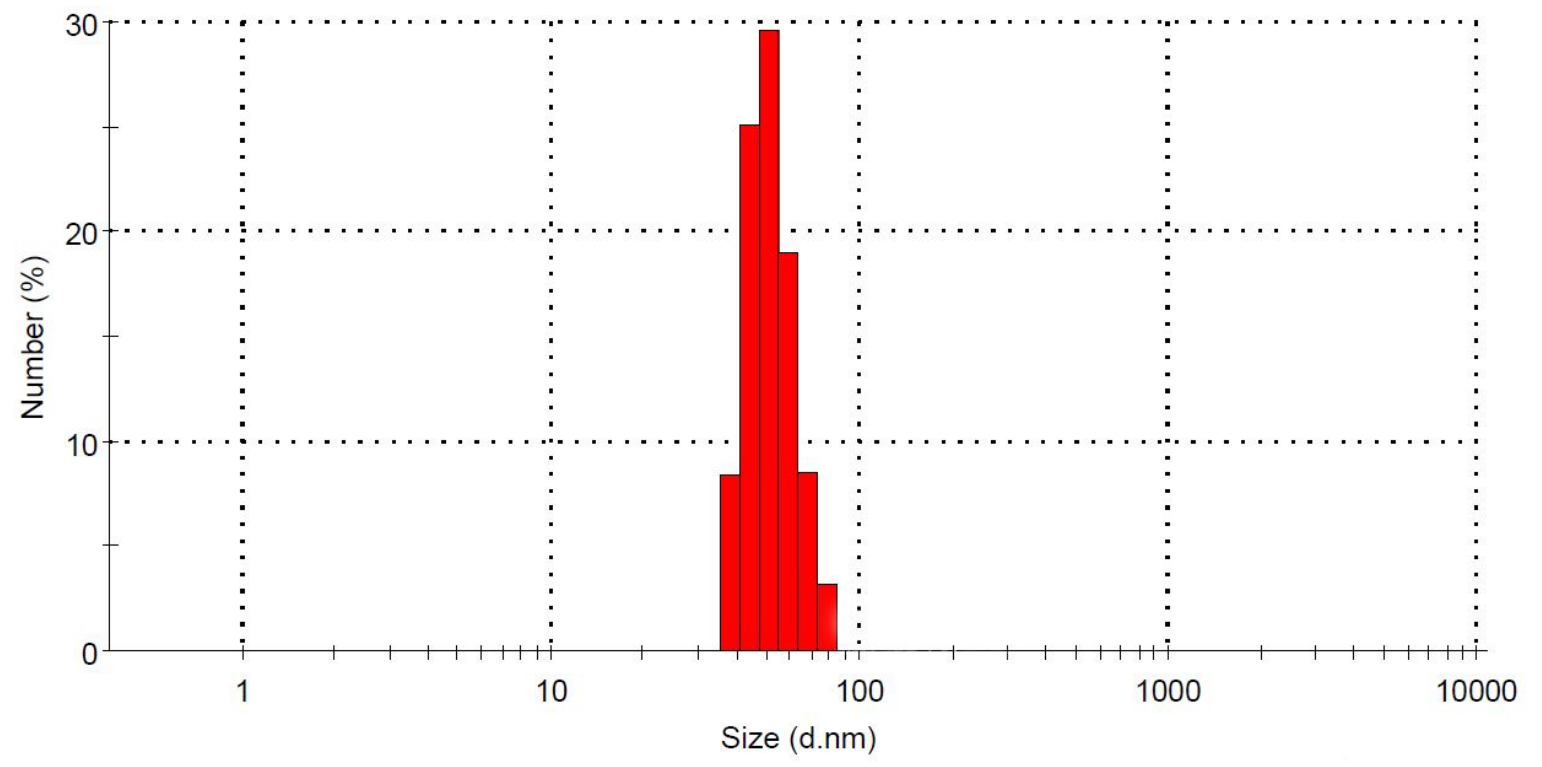

Figure $\mathrm{S} 1 . \mathrm{Fe}_{3} \mathrm{O}_{4} \mathrm{NPs}$ size distribution ${ }^{1}$. 


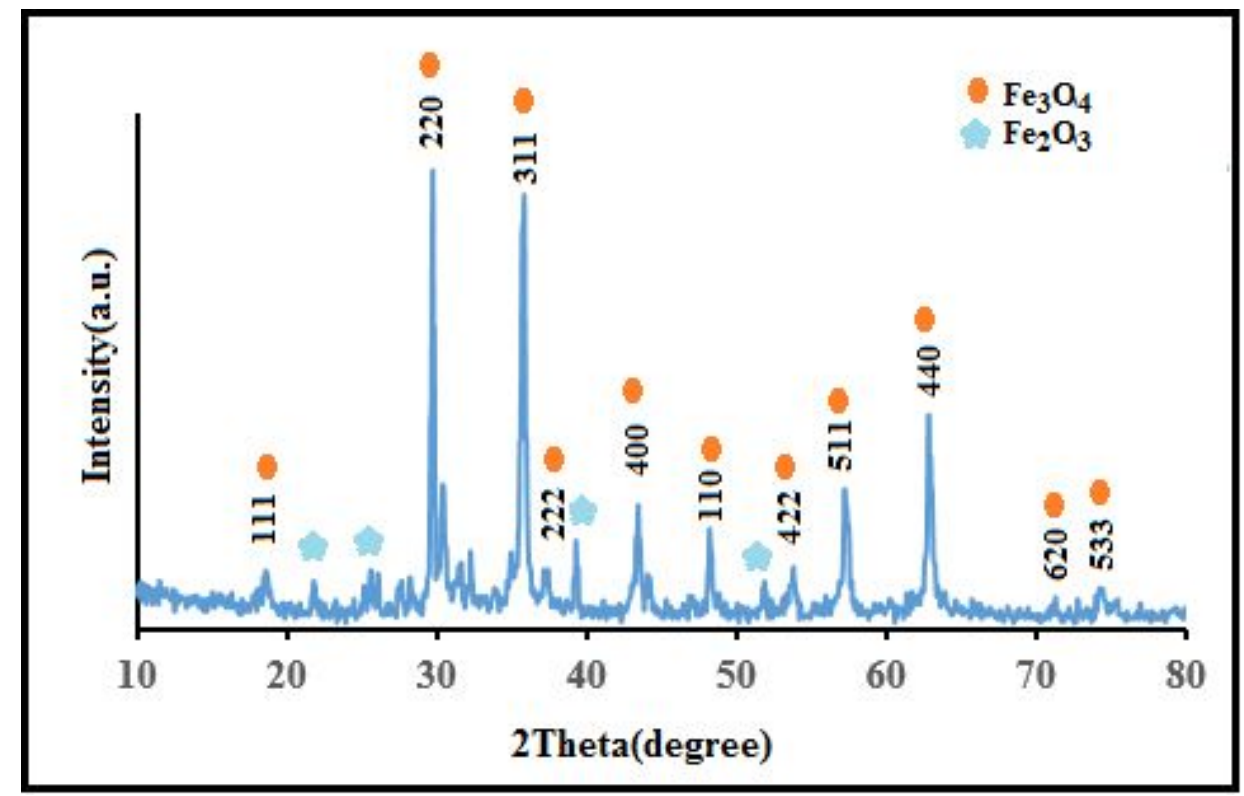

Figure S2. XRD pattern of the synthesized NPs ${ }^{1}$. 


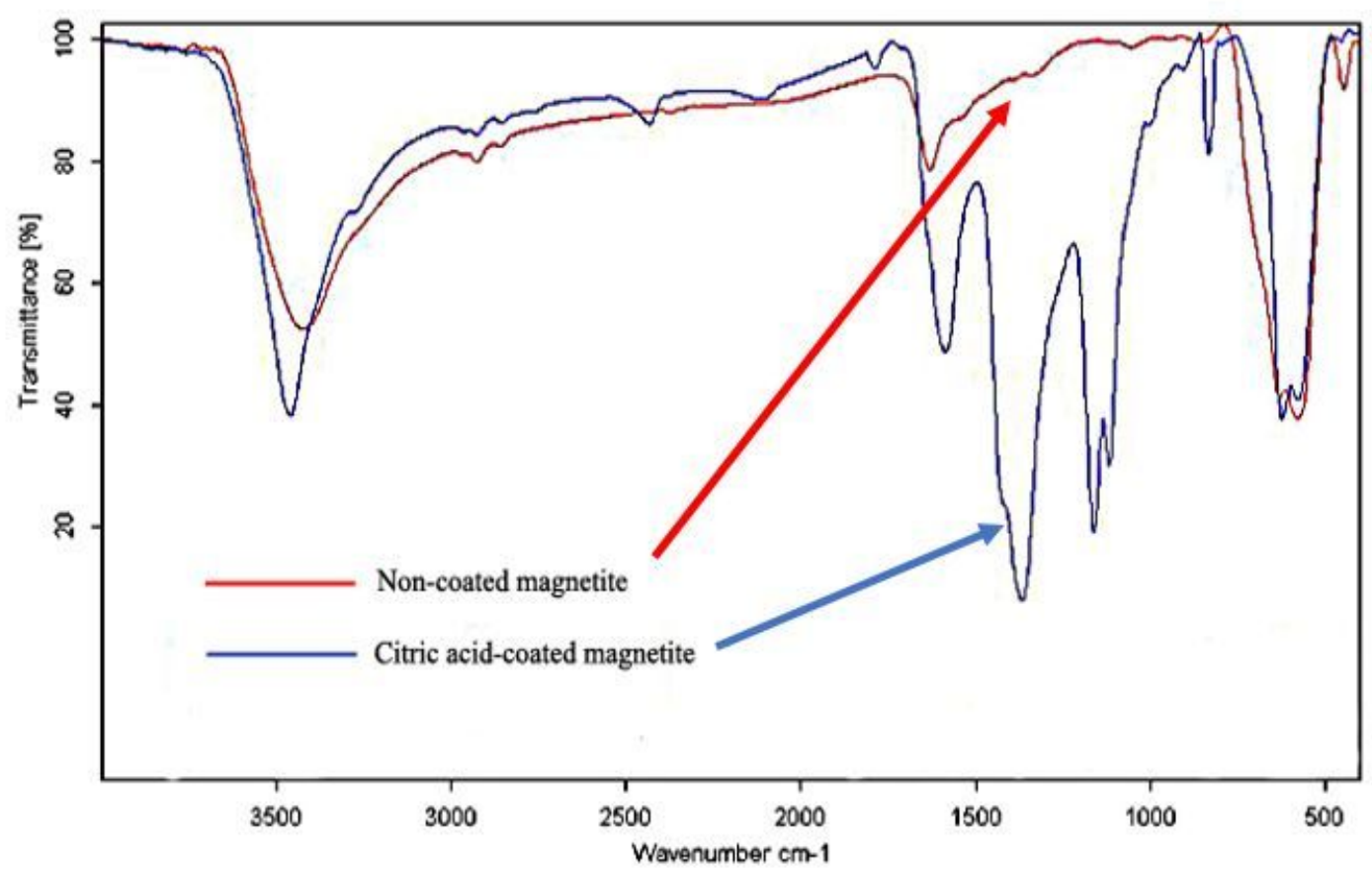

Figure S3. FTIR spectra of the synthesized NPs ${ }^{1}$.

1. Divandari, H.; Hemmati-Sarapardeh, A.; Schaffie, M.; Ranjbar, M., Integrating synthesized citric acid-coated magnetite nanoparticles with magnetic fields for enhanced oil recovery: Experimental study and mechanistic understanding. Journal of Petroleum Science and Engineering 2019, 174, 425-436. 